Cite this: Phys. Chem. Chem. Phys., $2014,16,14236$

Received 28th April 2014, Accepted 2nd June 2014

DOI: $10.1039 / c 4 c p 01837 k$

www.rsc.org/pccp

\title{
Computational study of structural properties of lithium cation complexes with carbamate-modified disiloxanes $\dagger$
}

\author{
Steffen Jeschke, ${ }^{\star a}$ Hans-Dieter Wiemhöfer ${ }^{a}$ and Christian Mück-Lichtenfeld ${ }^{b}$
}

\begin{abstract}
Lithium cation solvation structures $\left[\mathrm{Li}(\mathrm{S})_{n=1-4}\right]^{+}$with ligands of cyclic or noncyclic carbamate-modified disiloxanes are optimized at B3LYP level of theory and compared to their corresponding simplified carbamates and to the organic carbonates ethylene carbonate (EC) and dimethyl carbonate (DMC). The electrostatic potentials (ESP) of these investigated carbonyl-containing solvents are mapped on the electron density surface. The maximum ESP is located at the $\mathrm{C}=\mathrm{O}$-oxygen, whereas the disiloxane functionality represents an unpolar residue. Natural Bond Orbitals (NBO) analysis reveals strong $\mathrm{n}(\mathrm{N}) \rightarrow \pi(\mathrm{C}=\mathrm{O})$ donor-acceptor interactions in carbamates which outrun dipolar properties. As a result, higher total binding energies $\left(\Delta E_{\mathrm{B}}\right)$ for solvation of $\mathrm{Li}^{+}$in carbamates $\left(-148 \mathrm{kcal} \mathrm{mol}^{-1}\right)$ are found than for carbonates $\left(-137 \mathrm{kcal} \mathrm{mol}^{-1}\right)$. Furthermore, the disiloxane moiety with its $\mathrm{Si}-\mathrm{O}$ bond is stabilized by $\mathrm{n}(\mathrm{O}) \rightarrow \sigma^{\star}(\mathrm{Si}-\mathrm{C})$ hyperconjugation that provides additional electron density to a nearby $\mathrm{SiCH}_{3}$ methyl group thus supporting an additional $\mathrm{SiCH}_{2}-\mathrm{H} \cdots \mathrm{Li}^{+}$coordination. The formation of all investigated solvation structures is exothermic. Owing to steric hindrance of noncyclic carbonyl-containing ligands and the bulky disiloxane functionality, the solvation structure $\left[\mathrm{Li}(\mathrm{S})_{3}\right]^{+}$is the preferred structure according to Gibbs free energy $\Delta G_{B}$ results.
\end{abstract}

\section{Introduction}

Liquid blends of organic carbonates, e.g. ethylene carbonate (EC; 1), propylene carbonate (PC), dimethyl carbonate (DMC; 2) or diethyl carbonate (DEC), are typical examples for non-aqueous solvents of liquid electrolytes used in lithium-ion battery systems. ${ }^{1}$ There have been large numbers of reports discussing these solvents and their electrochemical properties, decomposition, ${ }^{2-5}$ cycling behaviour and formation of first-shell solvation structures with lithium cations. ${ }^{6}$ Regarding the development of alternative liquid electrolytes to improve safety, low viscosity siliconcontaining liquids have drawn much attention due to their nontoxic nature and reduced flammability. So far, published results mainly focus on carbonate-modified ${ }^{7-9}$ and ethylene glycol-modified $^{10-15}$ di-/trisiloxanes and silyl ether compounds. ${ }^{16-18}$ Their structure derived from EC/PC, and from poly(ethylene oxide) (PEO), an ion-conducting polymer already widely used in solid polymer electrolytes (SPE) since 1973. ${ }^{19}$

\footnotetext{
${ }^{a}$ Institute of Inorganic and Analytical Chemistry, University Münster, Corrensstr. 28/30, 48149 Münster, Germany. E-mail: s.jeschke@wwu.de,hdw@wwu.de

${ }^{b}$ Organic Chemistry Institute and Center for Multiscale Theory and Computation, University Münster, Correnstr. 40, 48149 Münster, Germany

$\dagger$ Electronic supplementary information (ESI) available: $\mathrm{C}=\mathrm{O}$ bond lengths, $\mathrm{C}=\mathrm{O}$-oxygen charges, cavity volumes and images of computed solvation structures. See DOI: 10.1039/c4cp01837k
}

Further improvement of safety issues may be achieved by application of SPEs since they replace flammable liquids completely. ${ }^{20,21}$ But so far, they suffer from poor ionic conductivity in a magnitude of $10^{-5} \mathrm{~S} \mathrm{~cm}^{-1}$ at ambient temperature. In order to increase the ionic conductivity of polysiloxane-based SPE systems, mixed ethylene glycol- and carbonate-modified polysiloxanes were prepared to introduce a high ability to dissociate lithium salts and increase the concentration of free ions in a polymer matrix. ${ }^{22,23}$

Nevertheless, the incorporated carbonate-moiety decreased the ionic conductivity due to increased viscosity and reduced segmental motion of the polymer matrix. The ionic transport properties of the SPE were inhibited by strong dipole-dipole interactions between the carbonate components. ${ }^{23}$

Recently, we have reported the synthesis of novel liquid carbamate-modified disiloxanes, ${ }^{24}$ as well as their application in porous PVDF-HFP membranes. ${ }^{25}$ These liquid materials reach an ionic conductivity in the magnitude of $10^{-4} \mathrm{~S} \mathrm{~cm}^{-1}$ at ambient temperature and are electrochemically stable up to $4.5 \mathrm{~V} v s . \mathrm{Li} / \mathrm{Li}^{+}$. Beside their application as alternative liquid electrolytes, we considered carbamate-modified disiloxanes as model compounds for the development of future SPEs, due to the decreased dielectric constant $\varepsilon$ of their lead structure $N$-methyloxazolidin-2-one (NMO, $3 ; \varepsilon=78) .{ }^{1}$ Therefore, compared to $\mathbf{1}(\varepsilon=90)^{1}$ and various carbonatemodified poly-/di-/trisiloxanes, weaker dipole-dipole interactions might arise in carbamate-modified polysiloxane-based SPEs. 


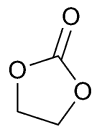

1

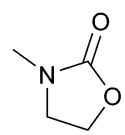

3

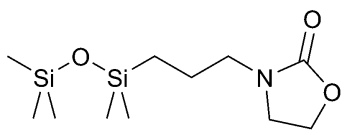

5
2

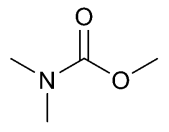

4

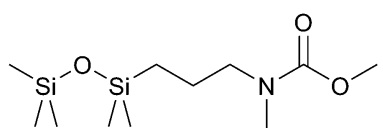

6

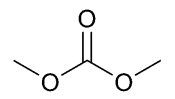

Fig. 1 Structures of investigated solvents $(S=1-6)$, including organic carbonates $\mathbf{1}$ and $\mathbf{2}$, simplified carbamates $\mathbf{3}$ and $\mathbf{4}$, and the corresponding carbamate-modified disiloxanes $\mathbf{5}$ and $\mathbf{6}$.

Herein, quantum-chemical calculations employing the density functional theory (DFT) have been performed to calculate the character and strength of the binding between the lithium ion and a number of carbonate and carbamate containing solvents ( $\mathrm{S}=$ 1-6; Fig. 1). Furthermore, electrostatic properties and population analysis were examined for all solvents. The organic carbonates $\mathbf{1}$ and $\mathbf{2}$ were considered as conventional references. The carbamates 3 and the noncyclic methyl dimethylcarbamate (4) were investigated as simplified carbamate models to identify influences of the disiloxanes functionality in their corresponding carbamate-modified disiloxanes 3-(3-(1,1,3,3,3-pentamethyldisiloxanyl)propyl)oxazolidin-2-one (5) and $N$-methyl methyl(3-(1,1,3,3,3-pentamethyldisiloxanyl)propyl) carbamate (6). In addition, the impact of cyclic and noncyclic carbonyl structures on the formation of $\mathrm{Li}^{+}$solvation structures was examined, directly. The computed properties may be helpful for the understanding of complex formation of carbamates and carbamate-modified disiloxanes, as well as for the development of future siloxane containing polymer electrolyte systems.

\section{Computational methodology}

All calculations were performed with the Gaussian 09 program package. ${ }^{26}$ The electronic ground state geometries of the studied lithium ion solvation structures $\left[\mathrm{Li}(\mathrm{S})_{n=1-4}\right]^{+}(\mathrm{S}=1-6$; Fig. 1) were optimized in gas phase at Becke's three-parameter hybrid $\operatorname{method}^{27}$ with the Lee-Yang-Parr correlation functional ${ }^{28}$ (B3LYP) level of theory without the presence of a counter anion. In order to verify the relative energy sequence of the optimized complexes, their single point energies were also calculated using $a b$ initio $\mathrm{HF}$ and MP2 methods. All calculations were performed using the $6-311 \mathrm{G}(\mathrm{d}, \mathrm{p})$ basis set ${ }^{29}$ providing a qualitative understanding of the complex energetics. The stability of all optimized solvation structures was verified by vibrational analysis; no imaginary vibrational frequencies were detected. No basis superposition error (BSSE) corrections have been applied.
Population analysis was performed by Natural Bond Orbital $(\mathrm{NBO})^{30-34}$ analysis and by analysis of electrostatic potentialderived charges (ESP) according to Merz-Singh-Kollman scheme. ${ }^{35,36}$ ESP results were used to compute maps of electrostatic potential.

\section{Results and discussion}

\section{Structures and geometries}

First, formations of the lithium ion solvation structures $\left[\mathrm{Li}(\mathrm{S})_{n=1-4}\right]^{+}$ ( $\mathrm{S}=\mathbf{1 - 6})$ were analysed. All investigated solvents contain a carbonyl group that reacts as a ligand by interacting with the cation via $\mathrm{C}=\mathrm{O}$-oxygen. This is consistent with other theoretical and spectroscopic IR and Raman studies regarding mixtures of lithium salts in 1 or $\mathrm{PC} .{ }^{37,38}$ As revealed by $\mathrm{IR}^{25}$ and $\mathrm{NMR}^{24}$ results examined for solvent $\mathbf{5}$, the carbamate moiety interacts with a lithium ion, similarly.

By coordinating the lithium ion and acting as a ligand, the solvent molecules 1-6 are deformed including a slightly stretched $\mathrm{C}=\mathrm{O}$ bond (see Fig. S1 of ESI $\dagger$ ). The strongest deformation of the ligands $\mathrm{C}=\mathrm{O}$ geometry in comparison to the free solvent molecule was found for the structure $\left[\operatorname{Li}(S)_{1}\right]^{+}$. Owing to a weaker interaction of the ligand with the cation, the deformation decreases with increasing coordination number. This result is consistent with the $\mathrm{Li}-\mathrm{O}$ bond length, as listed in Table 1, and has already been observed in other calculated lithium ion complex structures. ${ }^{2,39}$ The proportionality between the coordination numbers and the averaged $\mathrm{Li}-\mathrm{O}$ bond lengths may be described, as for dimethyl sulfoxid (DMSO) solvation structures, ${ }^{39}$ by the exponential function

$$
\bar{d}_{\mathrm{Li}-\mathrm{O}}=a \exp (b n)
$$

Table $1 \mathrm{Li}-\mathrm{O}$ bond lengths and $\mathrm{O}-\mathrm{Li}-\mathrm{O}$ angles of complex structures optimized at B3LYP/6-311G(d,p) level of theory

\begin{tabular}{|c|c|c|c|c|c|c|}
\hline \multirow[b]{2}{*}{ Complex } & \multicolumn{6}{|c|}{ Solvent S } \\
\hline & 1 & 2 & 3 & 4 & 5 & 6 \\
\hline \multicolumn{7}{|c|}{ Li-O bond lengths $(\AA)$} \\
\hline$\left[\mathrm{Li}(\mathrm{S})_{1}\right]^{+}$ & 1.733 & 1.729 & 1.730 & 1.705 & 1.739 & 1.736 \\
\hline \multirow{2}{*}[\mathrm{Li}(\mathrm{S})_{2}]{$^{+}$} & 1.786 & 1.780 & 1.794 & 1.763 & 1.784 & 1.763 \\
\hline & 1.786 & 1.780 & 1.794 & 1.763 & 1.795 & 1.760 \\
\hline \multirow[t]{3}{*}[\mathrm{Li}(\mathrm{S})_{3}]{$^{+}$} & 1.850 & 1.851 & 1.860 & 1.842 & 1.869 & 1.841 \\
\hline & 1.850 & 1.851 & 1.868 & 1.842 & 1.849 & 1.841 \\
\hline & 1.851 & 1.848 & 1.870 & 1.843 & 1.866 & 1.85 \\
\hline \multirow[t]{4}{*}[\mathrm{Li}(\mathrm{S})_{4}]{$^{+}$} & 1.940 & 1.942 & 1.944 & 1.958 & 1.917 & 1.964 \\
\hline & 1.942 & 1.962 & 1.942 & 1.956 & 1.953 & 1.976 \\
\hline & 1.943 & 1.961 & 1.935 & 1.960 & 1.947 & 1.963 \\
\hline & 1.937 & 1.961 & 1.921 & 1.962 & 1.950 & 1.958 \\
\hline \multicolumn{7}{|c|}{$\mathrm{O}-\mathrm{Li}-\mathrm{O}$ angles (deg) } \\
\hline$\left[\operatorname{Li}(\mathrm{S})_{2}\right]^{+}$ & 180.0 & 180.0 & 179.5 & 178.5 & 170.7 & 177.4 \\
\hline \multirow[t]{3}{*}[\mathrm{Li}(\mathrm{S})_{3}]{$^{+}$} & 119.7 & 120.0 & 120.0 & 119.4 & 118.9 & 121.7 \\
\hline & 120.0 & 120.0 & 119.0 & 119.8 & 120.0 & 118.5 \\
\hline & 120.3 & 120.0 & 121.0 & 120.8 & 121.0 & 119.7 \\
\hline \multirow{6}{*}[\mathrm{Li}(\mathrm{S})_{4}]{$^{+}$} & 107.4 & 110.3 & 112.3 & 110.9 & 109.8 & 110.4 \\
\hline & 108.1 & 109.3 & 108.2 & 107.5 & 107.5 & 111.9 \\
\hline & 107.7 & 108.5 & 103.7 & 111.7 & 108.4 & 109.7 \\
\hline & 113.5 & 116.6 & 110.6 & 106.7 & 117.9 & 105.4 \\
\hline & 106.9 & 108.5 & 112.3 & 110.9 & 105.4 & 106.1 \\
\hline & 113.3 & 103.5 & 112.7 & 109.9 & 107.3 & 113.4 \\
\hline
\end{tabular}



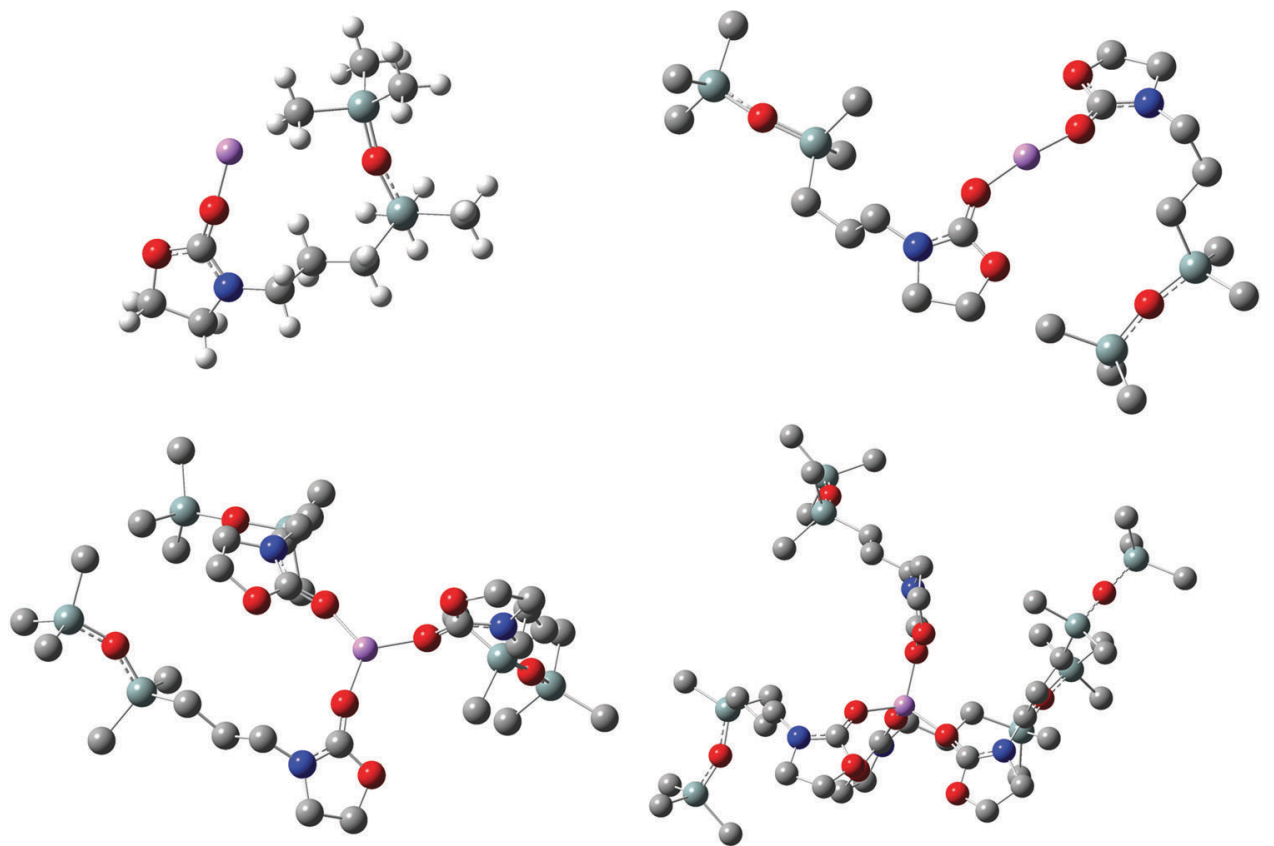

Fig. 2 Geometries of solvation structures $\left[\mathrm{Li}(\mathbf{5})_{n=1-4}\right]^{+}$optimized at B3LYP/6-311G(d,p) level of theory. Hydrogen atoms are not shown in all structures for clarity.

where $a=1.663 \AA$, $b=0.037$ for $1, a=1.649 \AA, b=0.041$ for 2 , $a=1.666 \AA, b=0.038$ for $3, a=1.617 \AA$ and $b=0.046$ for 4 , $a=1.669 \AA, b=0.037$ for 5 and $a=1.644 \AA$ and $b=0.042$ for 6, respectively. Considering the structure of the coordinating ligands 1-6, values of $b=0.0375 \pm 0.005$ were found for cyclic carbonyl moieties $\mathbf{1}, 3$ and 5, whereas a value of $b=0.043 \pm 0.0026$ was determined for the noncyclic carbonyls 2 , 4 and 6.

No symmetry was imposed in the geometry optimizations of the complexes $\left[\mathrm{Li}(\mathrm{S})_{n}\right]^{+}$. According to O-Li-O angles of approximately $\approx 109^{\circ}, \approx 120^{\circ}$ and $\approx 180^{\circ}$ a tetrahedral, trigonal planar and linear geometry were obtained for $n=4 \rightarrow 2$, respectively.

In Fig. 2, the optimized geometries of solvation structures $\left[\operatorname{Li}(5)_{n=1-4}\right]^{+}$are illustrated. The carbamate functionality interacts with $\mathrm{Li}^{+}$via $\mathrm{C}=\mathrm{O}$-oxygen, whereas the disiloxane moieties with its $\mathrm{SiCH}_{3}$-groups are rearranged with minimal repulsion around the complex centre. Furthermore, the linear nature of the $\mathrm{Si}-\mathrm{O}-\mathrm{Si}$ functionality with approximately $160^{\circ}-180^{\circ}$ is visible. $^{40,41}$ This solvation structure is consistent with previously presented results regarding the ionic conductivity of carbamate-modified disiloxanes. ${ }^{24}$ Since $\mathrm{Li}^{+}$transport in liquids occurs mostly by diffusion of ions including their first shell of solvation (vehicular mechanism), ${ }^{21}$ the bulky disiloxane moiety increases the size of the solvation structure significantly (see Table T2 of ESI $\dagger$ ). A larger solvation structure is equivalent to a larger van der Waals surface for intermolecular interactions and therefore increases the viscosity and decreases the vehicular diffusion, respectively. Comparing the ionic conductivity of 5 and $6\left(10^{-4} \mathrm{~S} \mathrm{~cm}^{-1}\right.$ at ambient temperature) to conventional liquid electrolytes composed of blends of $\mathbf{1}$ and $2\left(10^{-2}-10^{-3} \mathrm{~S} \mathrm{~cm}^{-1}\right)$, the deviation in performance is a result of the different sizes of their corresponding $\mathrm{Li}^{+}$solvation structures.

\section{Analysis of electronic structures}

The electronic structure of solvents 1-6 has been analysed using two different approaches: (a) via NBO and (b) ESP. The NBO method examines the charge distribution close to the atom centres, whereas the ESP method is better suited to reproduce the coulombic effects of the adjacent ligands coordinating the lithium ion.

In Fig. 3, the isodensity surfaces (isoval $=0.002$ ) of the B3LYP-optimized structures of solvents 1-6 were mapped with their computed electrostatic potentials. The highest negative potential (red) is always located at the $\mathrm{C}=\mathrm{O}$ functionality. An increase in $\mathrm{ESP}_{\max }$ is observed in the ranking $2<\mathbf{1}<\mathbf{6}<\mathbf{4}<$ $3 \approx 5$, which indicates a structural relation: (a) carbonates 1 and 2 have lower potentials than carbamates 3-6, (b) noncyclic compounds 2, 4 and 6 have lower potentials than their cyclic counterparts 1, 3 and 5. Furthermore, in the five-membered ring structures of $\mathbf{1 , 3}$ and $\mathbf{5}$, the potentials are clearly polarized with the lowest values (blue) located at the $\mathrm{CH}_{2}-\mathrm{CH}_{2}$ moieties. This result illustrates the dipolar character of commercially available solvents $\mathbf{1}$ and 3, which corresponds to their large dipole moments of $4.6 \mathrm{D}$ and $4.5 \mathrm{D}$, respectively. ${ }^{1}$ In noncyclic solvents 2, 4 and 6 the charge polarization appears less pronounced, indicating lower dipole moments $(0.8 \mathrm{D} \text { for } 2)^{1}$ which results in inert properties. Additionally, the ESP maps verify that the dipolar properties of the oxazolidinone moiety in $\mathbf{5}$, as well as the inert character of the carbamate moiety in compound 6, remain unaffected by the disiloxane functionality. According to the colour code, the disiloxane with its $\mathrm{SiCH}_{3}$ groups represents an unpolar region (green), predominantly. 

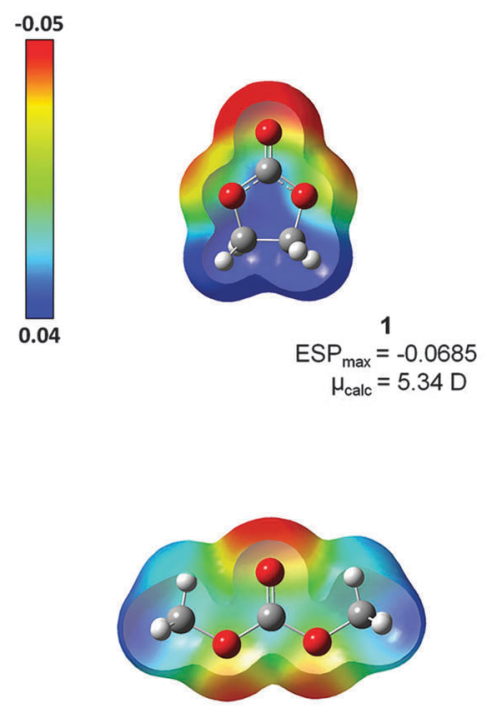

$$
\begin{array}{rl}
2 & 2 \\
\mathrm{ESP}_{\max } & =-0.0594 \\
\mu_{\text {calc }} & =0.30 \mathrm{D}
\end{array}
$$

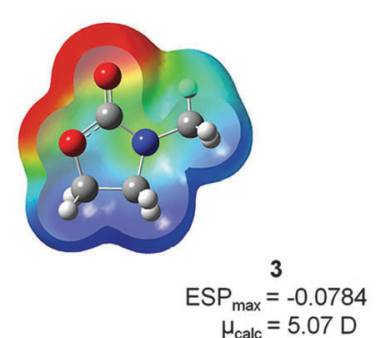

$\mu_{\text {calc }}=5.07 \mathrm{D}$
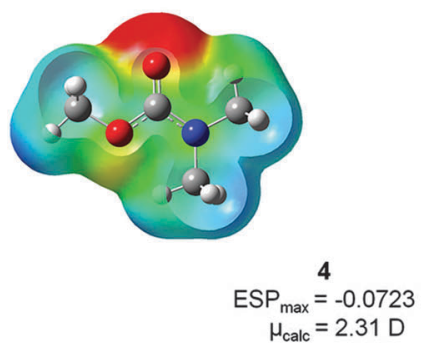
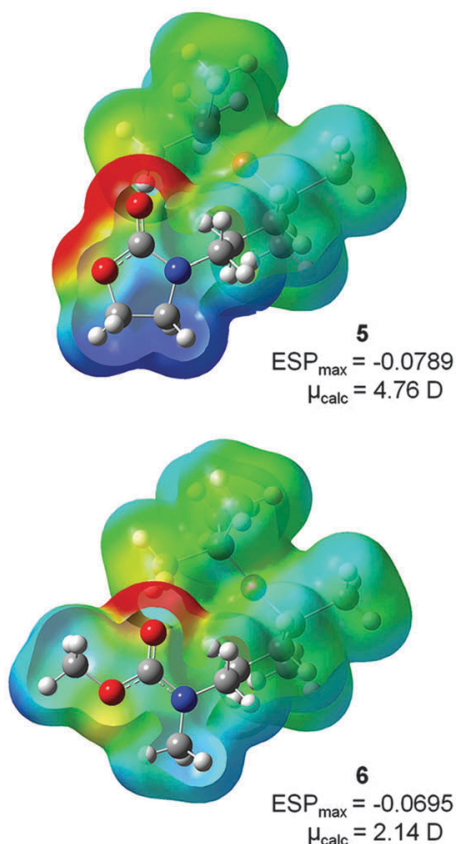

Fig. 3 Electron density maps from total SCF B3LYP density (isoval $=0.002$; mapped with ESP) for investigated solvents 1-6 with their values of maximum ESP (ESP $\left.P_{\text {max }}\right)$ and calculated dipole moments ( $\left.\mu_{\text {calc }}\right)$.

Regarding NBO population analysis, the charges of the $\mathrm{N}-\mathrm{C}(\mathrm{O})-\mathrm{O}$ fragment in the corresponding pairs of isolated $\mathbf{3 / 5}$ and $\mathbf{4} / \mathbf{6}$ are almost identical (see Table T1 in ESI $\dagger$ ). The atomic charges of $\mathrm{C}=\mathrm{O}$-oxygen and $\mathrm{Li}^{+}$of the isolated solvents and their solvation structures $\left[\mathrm{Li}(\mathrm{S})_{n=1-4}\right]^{+}(\mathrm{S}=\mathbf{1 - 6})$ are plotted in Fig. $4 \mathrm{a}$ and $\mathrm{b}$, respectively. By comparing $\mathrm{C}=\mathrm{O}$-oxygen charge values, structural relations become evident again: (a) carbamate $\mathrm{C}=\mathrm{O}$-oxygens are more negative than in carbonates and $(\mathrm{b})$ in noncyclic compounds the $\mathrm{C}=\mathrm{O}$-oxygen is more negative than in cyclic carbonyl structures (+I effect). As a result, an increase in negative atomic charge at this oxygen is observed in the ranking $\mathbf{1}<\mathbf{3} \approx \mathbf{5}<\mathbf{2}<\mathbf{4} \approx \mathbf{6}$. For solvation structures of $n=1$, the lowest NBO charge in the magnitude of -0.8 to -0.9 were observed. With $n=2 \rightarrow 4$ the negative charge values decrease reaching a magnitude of -0.6 to -0.7 . This result is consistent

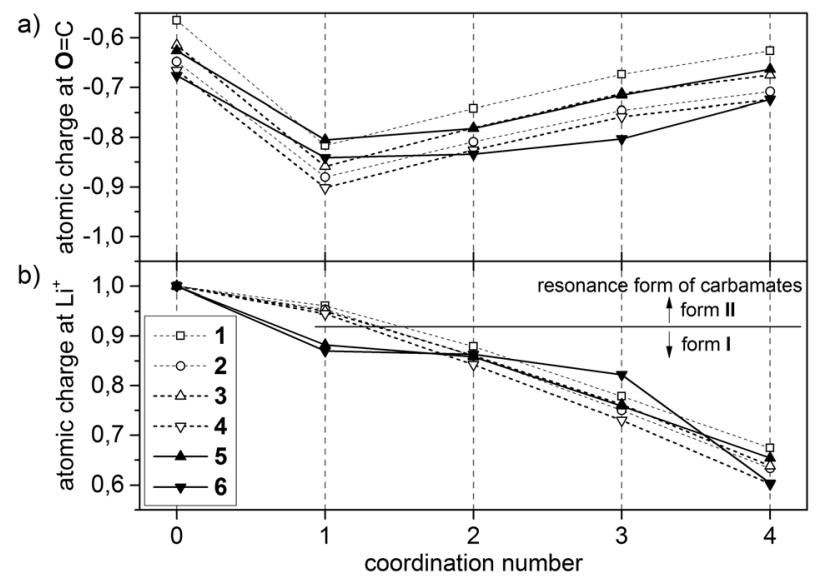

Fig. 4 NBO atomic charges of (a) $\mathrm{C}=\mathrm{O}$-oxygen and (b) $\mathrm{Li}^{+}$. with the described geometry changes. In complexes of type $\left[\mathrm{Li}(\mathrm{S})_{1}\right]^{+}$the $\mathrm{C}=\mathrm{O}$-oxygen of a single ligand provides electrons for a strong, short, dative bond to the cation, which requires a high negative charge at this oxygen-position. Compared to donoracceptor interactions, the carbamate unit has two resonance forms, Fig. 5. The lone pair of the $\mathrm{sp}^{2}$ hybridized nitrogen $\left(\mathrm{sp}^{1.8}\right.$ according to NBO analysis) overlaps effectively with the carbonyl group and provides additional electron density by $\mathrm{n}(\mathrm{N}) \rightarrow \pi(\mathrm{C}=\mathrm{O})$ donor-acceptor interactions, causing a delocalization of the nitrogen's lone pairs into the $\pi$-system. By increasing the $\mathrm{C}=\mathrm{N}$ double bond character (II), the electron density at the $\mathrm{C}=\mathrm{O}$ oxygen is maximized. According to NBO analysis, resonance structure II is only preferred in complexes of $\left[\mathrm{Li}(\mathrm{S})_{1}\right]^{+}(\mathrm{S}=\mathbf{3}, \mathbf{4})$, whereas carbamate-modified disiloxanes $(S=\mathbf{5}, \mathbf{6})$ prefer resonance structure $\mathbf{I}$. Moreover, the NBO charge at $\mathrm{Li}^{+}$is reduced by $7 \%$ in presence of a single disiloxane ligand (Fig. $4 \mathrm{~b}$ ). This is due to an additional stabilization of $\mathrm{Li}^{+}$by intramolecular donor-acceptor interactions between two hydrogens $\mathrm{H}^{\mathrm{a}}$ of a $\mathrm{SiCH}_{3}$ group and the cation (Fig. 6 and Table 2). Via this $\mathrm{SiCH}_{2}-$ $\mathrm{H} \cdots \mathrm{Li}^{+}$interaction, the cation polarizes the $\mathrm{Si}-\mathrm{C}$ bond. In order to provide the required electron density in the donating methyl group, the contribution of the $\mathrm{Si}$ atom in the corresponding $\mathrm{Si}-\mathrm{C}$ bond decreases from $\approx 29 \%$ to $24 \%$ (Table 3 ). In return, the $\mathrm{Si}$ contribution to the $\sigma^{*}(\mathrm{Si}-\mathrm{C})$ increases from $71 \%$ to $76 \%$,

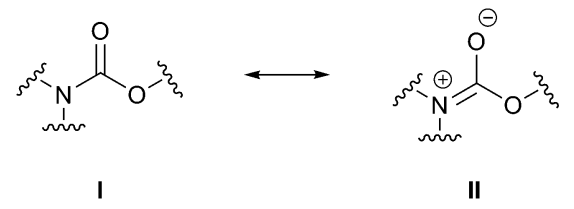

Fig. 5 Resonance structures for the carbamate group in 3-6. 


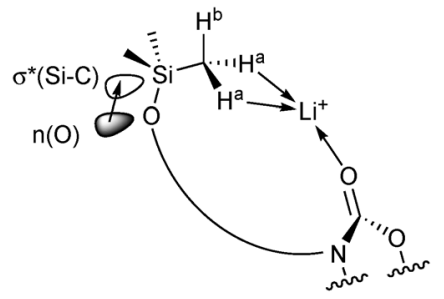

$$
\begin{aligned}
\mathrm{n}(\mathrm{O}) & \longrightarrow \sigma^{*}(\mathrm{Si}-\mathrm{C}) 6-8 \mathrm{kcal} / \mathrm{mol} \\
\sigma\left(\mathrm{C}-\mathrm{H}^{\mathrm{a}}\right) & \longrightarrow 2 \mathrm{~s}\left(\mathrm{Li}^{+}\right) \sim 4 \mathrm{kcal} / \mathrm{mol}
\end{aligned}
$$

Fig. 6 Coordination of $\mathrm{Li}^{+}$by interacting with a carbamate-modified disiloxane. The interaction stabilizes the solvation structures $\left[\mathrm{Li}(\mathrm{S})_{1}\right]^{+}$ $(S=5,6)$ by the given energies.

Table 2 Atomic charges from NBO method for simplified carbamate solvents $\mathbf{3}$ and $\mathbf{4}$ and carbamate-modified disiloxanes $\mathbf{5}$ and $\mathbf{6}$ in their $\left[\mathrm{Li}(\mathrm{S})_{1}\right]^{+}$solvation structures. Hydrogens $\mathrm{H}^{\mathrm{a}}$ of a $\mathrm{SiCH}_{3}$-group provide additional electron density to interact with $\mathrm{Li}^{+}$

\begin{tabular}{llllll}
\hline$\left[\mathrm{Li}(\mathrm{S})_{1}\right]^{+}$ & $\mathrm{Li}^{+}$ & $\mathrm{C}=\mathrm{O}$ & $\mathrm{H}^{\mathrm{a}}$ & $\mathrm{H}^{\mathrm{b}}$ & $\mathrm{SiCH}{ }_{2}^{\mathrm{a}} \mathrm{H}^{\mathrm{b}}$ \\
\hline $\mathrm{S}=\mathbf{3}, \mathbf{4}$ & 0.95 & -0.62 & - & - & - \\
$\mathrm{S}=\mathbf{5}, \mathbf{6}$ & 0.88 & -0.67 & 0.20 & 0.24 & -1.13 \\
\hline
\end{tabular}

Table 3 Contributions of the Si atom in bonds with normal $\left(\mathrm{CH}_{3}\right)$ and a donating methyl group $\left(\mathrm{CH}_{2}^{\mathrm{a}} \mathrm{H}^{\mathrm{b}}\right)$, and energy of stabilization by hyperconjugation $E_{\mathrm{H}}$ in $\mathrm{kcal} \mathrm{mol}^{-1}$

\begin{tabular}{lllll}
\hline & \multicolumn{2}{c}{ Pure 5, 6 } & & \multicolumn{2}{l}{$\left[\mathrm{Li}(\mathrm{S})_{1}\right]^{+}(\mathrm{S}=\mathbf{5 ,}, \mathbf{6})$} \\
\cline { 2 - 2 } & $\mathrm{SiCH}_{3}$ & & $S i \mathrm{CH}_{3}$ & $S i \mathrm{CH}_{2}^{\mathrm{a}} \mathrm{H}^{\mathrm{b}}$ \\
\hline$\sigma(\mathrm{Si}-\mathrm{C})$ & $28 \%$ & & $29 \%$ & $24 \%$ \\
$\sigma^{*}(\mathrm{Si}-\mathrm{C})$ & $72 \%$ & & $71 \%$ & $76 \%$ \\
$E_{\mathrm{H}}\left(\mathrm{n}(\mathrm{O}) \rightarrow \sigma^{*}(\mathrm{Si}-\mathrm{C})\right)$ & $6.6-7.3$ & $7.1-8.0$ & $8.1-8.6$
\end{tabular}

stabilized by a preferred $\mathrm{n}(\mathrm{O}) \rightarrow \sigma^{*}(\mathrm{Si}-\mathrm{C})$ hyperconjugation of the nearby $\mathrm{Si}-\mathrm{O}$ bond $\left(>8.1 \mathrm{kcal} \mathrm{mol}^{-1}\right)$.

Similar to literature, ${ }^{41}$ the NBO analysis of the $\mathrm{Si}-\mathrm{O}-\mathrm{Si}$ unit reveals a single $\mathrm{Si}-\mathrm{O}$ bond with only $14 \%$ contribution of the $\mathrm{Si}$ atoms. Additionally, the Si-O bond is stabilized by $\mathrm{n}(\mathrm{O}) \rightarrow$ $\sigma^{*}(\mathrm{Si}-\mathrm{C})$ hyperconjugation implying a partial double bond character of $\mathrm{Si}-\mathrm{O}$. This is consistent with the observed linear nature of the $\mathrm{Si}-\mathrm{O}-\mathrm{Si}$ bond. Depending on the exact angle, each hyperconjugation stabilizes the disiloxane by 6 to $8 \mathrm{kcal} \mathrm{mol}^{-1}$. An angle of nearly $180^{\circ}$ is favoured due to better interaction of $\mathrm{n}(\mathrm{O}) \rightarrow \sigma^{*}(\mathrm{Si}-\mathrm{C})$ causing higher stabilization energies.

For $n=2 \rightarrow 4$, the NBO charge of $\mathrm{Li}^{+}$decreases due to more ligands providing electron density for the dative bond to the cation. This is consistent with geometry results. For all carbamates, resonance structure $\mathbf{I}$ is preferred for all corresponding complexes.

\section{Energetics and cluster stabilization}

In order to estimate the energetic aspects of $\left[\mathrm{Li}(\mathrm{S})_{n=1-4}\right]^{+}(\mathrm{S}=\mathbf{1 - 6})$ formation, the total binding energies $\left(\Delta E_{\mathrm{B}}\right)$ of the solvation structures were calculated by subtracting the energy of a given cluster from the summed energies of its constituting ingredients:

$$
\Delta E_{\mathrm{B}}=E\left[\mathrm{Li}^{+}(\mathrm{S})_{n}\right]-\left(E\left[\mathrm{Li}^{+}\right]+E[\mathrm{~S}] \times n\right)
$$

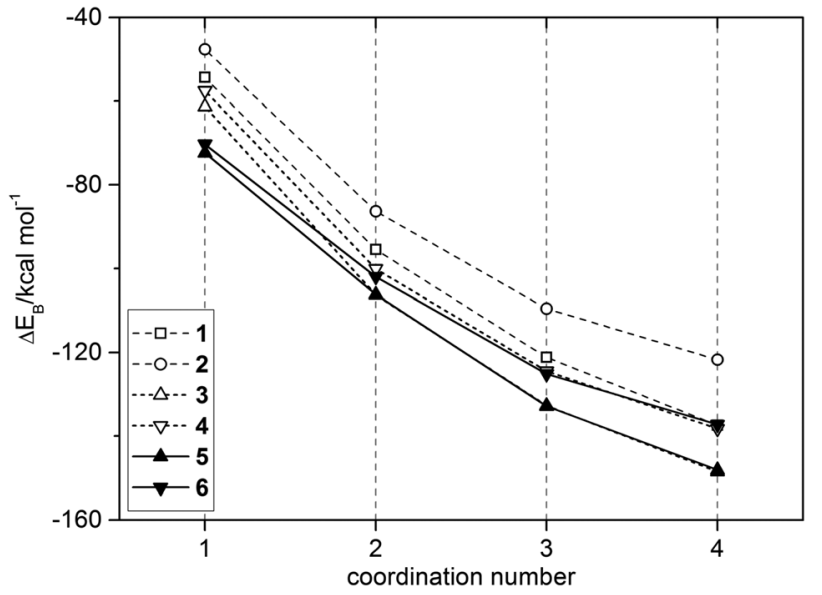

Fig. 7 Total binding energies $\Delta E_{\mathrm{B}}$ of $\left[\mathrm{Li}(\mathrm{S})_{n=1-4}\right]^{+}(\mathrm{S}=1-\mathbf{6})$ as a function of coordination number obtained from B3LYP/6-311G(d,p) calculations.

The computed binding energies $\Delta E_{\mathrm{B}}$ of B3LYP/6-311G(d,p) optimized solvation structures are shown in Fig. 7 and listed in Table 4 alongside their single point energies at $\mathrm{HF} / 6-311 \mathrm{G}(\mathrm{d}, \mathrm{p}) / /$ B3LYP/6-311G(d,p) and MP2/6-311G(d,p)//B3LYP/6-311G(d,p) levels of theory. The coordination number of the central lithium cation is directly related to the stability of the cluster. The larger the number of Li-O interactions $n=1 \rightarrow 4$, the more stable the cluster is, as implied by more negative values of $\Delta E_{\mathrm{B}}$. Energies calculated by the HF-method are similar to B3LYPresults with a deviation of $2 \mathrm{kcal} \mathrm{mol}^{-1}$ at maximum. For MP2results, a more significant deviation up to $9 \%$ compared to B3LYP-results was obtained. Nevertheless, the ranking of energies for complexes with $n=2 \rightarrow 42<1 \approx 6 \approx 4<3 \approx 5$ was observed for the B3LYP-, HF- and MP2-methode, which verifies the structural relation implied by analysis of the electronic structure: (a) $\Delta E_{\mathrm{B}}$ of carbonates $\mathbf{1}$ and $\mathbf{2}$ are weaker than those of carbamates 3-6 and (b) $\Delta E_{\mathrm{B}}$ of noncyclic carbonyls 2,4 and 6 are weaker than for their cyclic counterparts $\mathbf{1}, 3$ and 5.

In fact, $\Delta E_{\mathrm{B}}$ of the noncyclic carbamates $\mathbf{4}$ and $\mathbf{6}$ are similar to that of $\mathbf{1}$. This result is quite surprising, because it indicates that donor properties, as revealed by NBO analysis, even of noncyclic carbamates $\mathbf{4}$ and $\mathbf{6}$ outrun the higher dipolar character of 1.

For a better understanding of the driving factors leading to formation of solvation structures, the total binding energy was separated in terms of solvent-solvent interactions, $\Delta E_{\mathrm{S}}$,

$$
\Delta E_{\mathrm{S}}=E\left[(\mathrm{~S})_{n}^{*}\right]-E[\mathrm{~S}] \times n
$$

and solute-solvent interactions, $\Delta E_{\mathrm{M}}$,

$$
\Delta E_{\mathrm{M}}=E\left[\mathrm{Li}^{+}(\mathrm{S})_{n}\right]-\left(E\left[\mathrm{Li}^{+}\right]+E\left[(\mathrm{~S})_{n}^{*}\right]\right)
$$

in accordance with a sequential energy decomposition scheme. ${ }^{42,43}$

Here, single point calculations of a supermolecule $\left[(\mathrm{S})_{n}{ }^{*}\right]$ were performed with the lithium cation removed at fixed geometry of $\left[\mathrm{Li}(\mathrm{S})_{n}\right]^{+}$. Since B3LYP is known for insufficient description of dispersive forces, ${ }^{44} \Delta E_{\mathrm{S}}$ represents repulsive interaction energies among the solvent molecules in the solvation structures, as well 
Table 4 Energy analysis for all $\left[L i(S)_{n}\right]^{+}$clusters: total $\left(\Delta E_{S}\right)$ and relative $\left(\Delta \Delta E_{S}\right)$ solvent-solvent interactions, total $\left(\Delta E_{M}\right)$ and relative $\left(\Delta \Delta E_{M}\right)$ solutesolvent interactions and total $\left(\Delta E_{\mathrm{B}}\right)$ and relative $\left(\Delta \Delta E_{\mathrm{B}}\right)$ binding energies; thermodynamic analysis at $298.15 \mathrm{~K}$ : total $\left(\Delta H_{\mathrm{B}}\right)$ and relative $\left(\Delta \Delta H_{\mathrm{B}}\right)$ heats of solvation and total $\left(\Delta G_{B}\right)$ and relative $\left(\Delta \Delta G_{B}\right)$ Gibbs free energies of solvation. All energies (in $\left.\mathrm{kcal} \mathrm{mol}^{-1}\right)$ were calculated using basis set 6-311G(d,p)

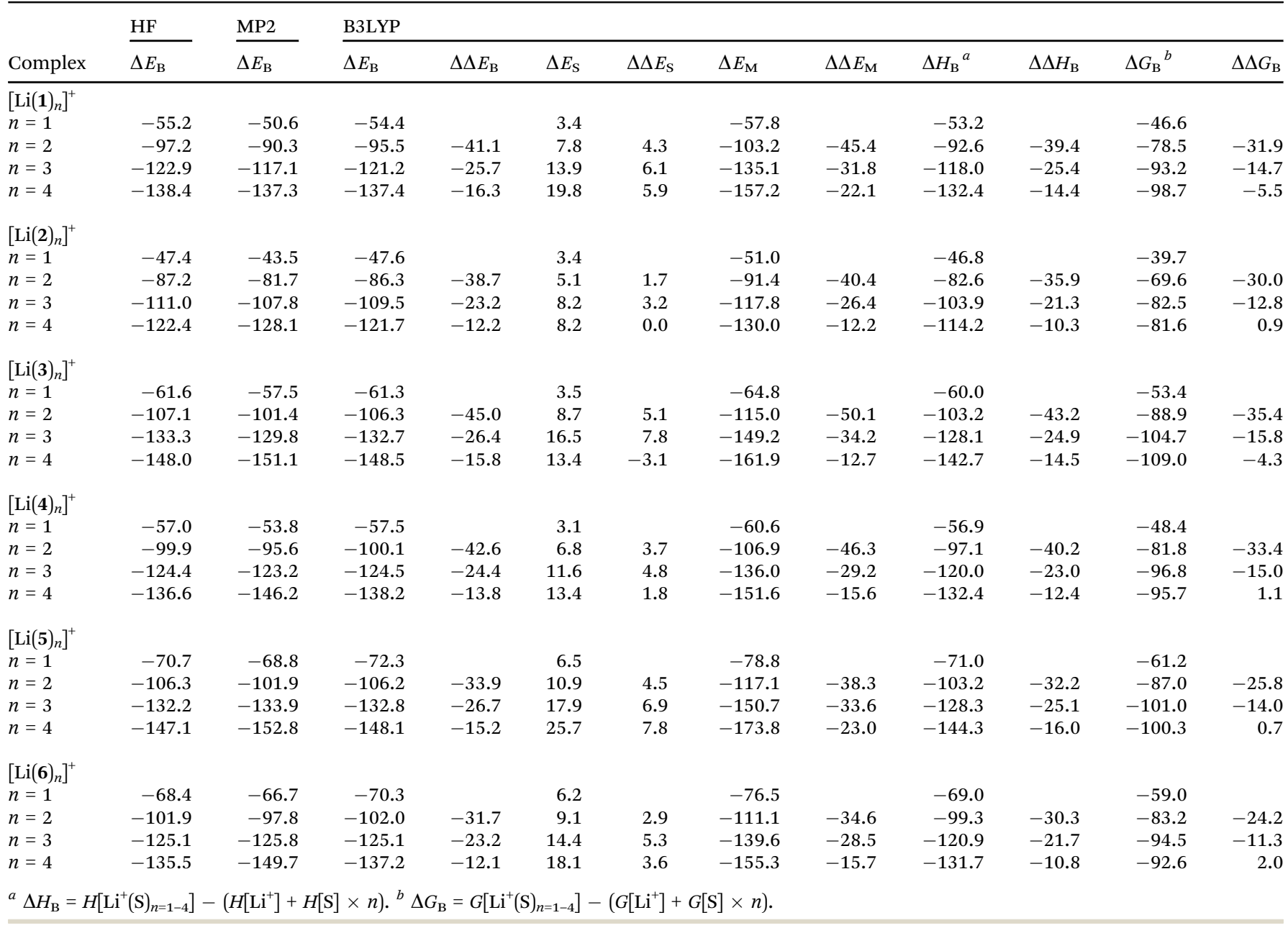

as their deformation energies. For $n=1, \Delta E_{\mathrm{S}}$ is equivalent to the deformation energy of the single solvent molecules. Thus, deformation energies of 3 to $3.5 \mathrm{kcal} \mathrm{mol}^{-1}$ were examined for solvents 1-4, whereas the $n=1$ structures of the disiloxanes 5 and 6 are slightly folded to enable $\mathrm{SiCH}_{2}-\mathrm{H} \cdots \mathrm{Li}^{+}$interaction (6.2 to $6.5 \mathrm{kcal} \mathrm{mol}^{-1}$ ). $\Delta E_{\mathrm{M}}$ is the interaction energy between the prepared solvent supermolecule and the lithium cation. The sum of both terms gives the total binding energy, $\Delta E_{\mathrm{B}}$ :

$$
\Delta E_{\mathrm{B}}=\Delta E_{\mathrm{S}}+\Delta E_{\mathrm{M}}
$$

The calculated energies, $\Delta E_{\mathrm{B}}, \Delta E_{\mathrm{S}}$ and $\Delta E_{\mathrm{M}}$, for ligands 1-6 are listed in Table 4. In general, lager magnitudes of the electrostatic solvent-solute interactions $\Delta E_{\mathrm{M}}$ make them the major stabilizing interactions for all solvation structures. But some differences in the energetic point of view were recognized. For instance, although structure $\left[\mathrm{Li}(3)_{4}\right]^{+}$presents a more negative $\Delta E_{\mathrm{B}}$ than structure $\left[\mathrm{Li}(3)_{3}\right]^{+}$, the latter is predicted to have a more positive $\Delta E_{\mathrm{S}}$, indicating a less stable $\left(3.1 \mathrm{kcal} \mathrm{mol}^{-1}\right)$ supermolecule structure of $\left[(3)_{3}{ }^{*}\right]$ compared to $\left[(3)_{4}^{*}\right]$. This observation remarks a notable impact of the carbamate structure in the study of clusters with ligands $\mathbf{3}$ and $\mathbf{4}$, because for noncyclic carbamate 4 the energies of the triangular supermolecule is slightly lower $\left(1.8 \mathrm{kcal} \mathrm{mol}^{-1}\right)$ than those of the tetrahedral, $n=4$, counterpart. Comparing $\Delta E_{\mathrm{S}}$ of carbamatemodified disiloxanes 5 and $\mathbf{6}$ with simplified carbamates 3 and 4, values of 18.1-25.7 kcal $\mathrm{mol}^{-1}$ were reached by 6 and 5 , respectively, due to much stronger repulsion of their adjacent, bulky disiloxane functionalities.

Regarding solvent-solute interactions $\Delta E_{\mathrm{M}}$, further differences between cyclic and noncyclic carbamate structure are noticeable. Energies $\Delta E_{\mathrm{M}}$ for $\left[\mathrm{Li}(3)_{n}\right]^{+}$are quite large $(-65$ to $-162 \mathrm{kcal} \mathrm{mol}^{-1}$ ) whereas values for 4 were calculated to be in a range of -61 to $-152 \mathrm{kcal} \mathrm{mol}^{-1}$. A similar effect of the ligand structure has been observed for carbonates where 1 represents a cyclic carbonyl and $\mathbf{2}$ its noncyclic counterpart.

According to computed heat of solvation $\Delta H_{\mathrm{B}}$, the formation of the complexes $\left[\mathrm{Li}(\mathrm{S})_{n=1-4}\right]^{+}(\mathrm{S}=\mathbf{1 - 6})$ is exothermic. For carbonate 1 , the calculated values of $\Delta \Delta H_{\mathrm{B}}$ agree with results predicted at B3PW91/6-31G(d) level of theory. ${ }^{2}$ In Fig. 8, the Gibbs free energies of reaction $\Delta G_{\mathrm{B}}$ of solvation structures $\left[\mathrm{Li}(\mathrm{S})_{n=1-4}\right]^{+}(\mathrm{S}=\mathbf{1 - 6})$ are shown. Since thermochemical properties of all solvation structure were calculated at a temperature 


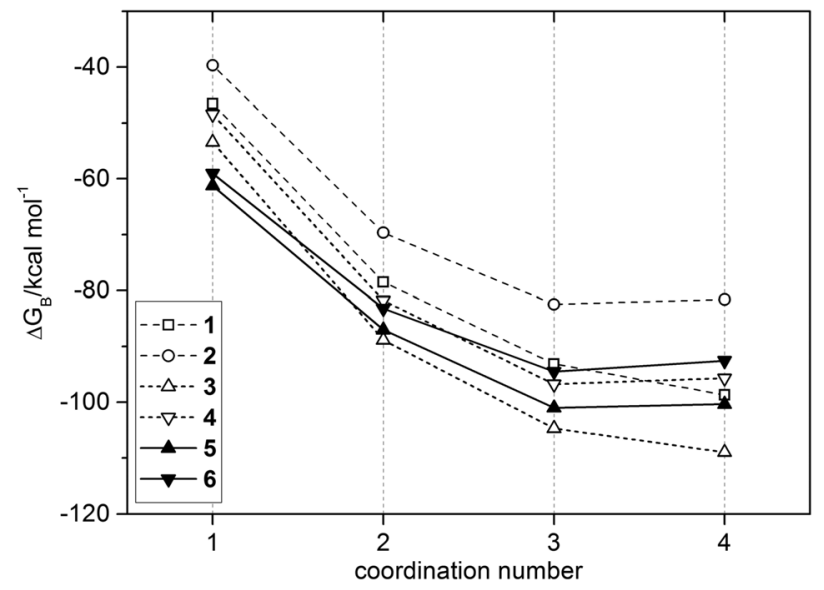

Fig. 8 Gibbs free energies of solvation $\Delta G_{B}$ of $\left[L i(S)_{n=1-4}\right]^{+}(S=1-6)$ as a function of the coordination number at $298.15 \mathrm{~K}$ obtained from B3LYP/ $6-311 G(d, p)$ frequency calculations.

of $25{ }^{\circ} \mathrm{C}(298.15 \mathrm{~K})$, entropy effects were recognizable. The relative Gibbs free energies of solvation $\Delta \Delta G_{\mathrm{B}}$ for $2,4,5$ and 6 at $n=4$ are positive or similar to values at $n=3$, which indicates that their preferred solvation structure is the three-coordinated complex. For $\mathbf{2}$ and $\mathbf{4}$, this is caused by the steric hindrance of the noncyclic carbonyl functionality, whereas $\mathbf{6}$ additionally, and 5 obviously suffer from the bulky disiloxane moiety. As expected, the four-coordinated complex is preferred for $\mathbf{1}^{2}$ and 3 .

\section{Conclusions}

Computed lithium cation solvation structures with carbamatemodified disiloxanes $\mathbf{5}$ and $\mathbf{6}$ were compared to their simplified carbamates $\mathbf{3}$ and $\mathbf{4}$, and to conventional liquid electrolyte components 1 and 2. Geometries of all investigated solvation structure were analysed. As visualized by ESP mapping, for all investigated solvents 1-6 the highest electron density is located at the $\mathrm{C}=\mathrm{O}$-oxygen, where the coordination to the lithium cation occurs. Furthermore, the solvents with cyclic carbonyl moieties 1, 3 and 5 have more dipolar characters than noncyclic carbonyls 2, 4 and 6 . The disiloxane functionality has no effect on the electronic structure of the carbamate moiety. Instead, the $\mathrm{Si}-\mathrm{O}-\mathrm{Si}$ stabilizes donor-acceptor interactions between hydrogens of a $\mathrm{SiCH}_{3}$ methyl group and the cation. As examined by NBO analysis, the required electron density of the $\sigma(\mathrm{Si}-\mathrm{C})$ bond is polarized towards the $\mathrm{C}$ atom, reducing the $\mathrm{Si}$ contribution to the $\mathrm{Si}-\mathrm{C}$ bond by $5 \%$. Therefore, the $\mathrm{n}(\mathrm{O}) \rightarrow \sigma^{*}(\mathrm{Si}-\mathrm{C})$ hyperconjugation of a $\mathrm{Si}-\mathrm{O}$ bond interacts predominantly with the corresponding $\sigma^{*}(\mathrm{Si}-\mathrm{C})$ orbitals. Considering results of Si-O-Si stabilized interactions between anions and a disiloxane functionality, ${ }^{41}$ the herein described stabilization of a lithium cation by $\mathrm{SiCH}_{2}-\mathrm{H} \cdots \mathrm{Li}^{+}$interaction remarks a notable capability of siloxane-containing electrolytes.

As a result of delocalization of the nitrogen's lone pair into the $\mathrm{C}=\mathrm{O} \pi$-system, $\mathrm{n}(\mathrm{N}) \rightarrow \pi(\mathrm{C}=\mathrm{O})$, and the $+\mathrm{I}$ effect of methyl groups nearby the noncyclic carbonyl moiety, higher atomic NBO charges for the $\mathrm{C}=\mathrm{O}$-oxygen were calculated for carbamates in the ranking $1<3 \approx 5<2<4 \approx 6$. According to the ranking $2<1<4 \approx 3<6 \approx 5$ of total binding energies $\Delta E_{\mathrm{B}}$ for solvation structures with $n=1 \rightarrow 2$, the greater atomic charge/ electron density at $\mathrm{C}=\mathrm{O}$-oxygens of carbamates 3-6 caused formation of more stable $\mathrm{Li}^{+}$solvation structures. For solvation structures with $n=3 \rightarrow 4$, calculated values of $\Delta G_{\mathrm{B}}$ indicated an increasing influence of steric hindrance in noncyclic carbonyl ligands 2, 4 and 6 as well as bulky disiloxanes 5 and 6 .

According to analysis of solvent-solvent, $\Delta E_{\mathrm{S}}$, and solutesolvent, $\Delta E_{\mathrm{M}}$, interactions, formation of solvent supermolecules requires energy due to repulsive forces, attenuating the electrostatic interactions $\Delta E_{\mathrm{M}}$ which are the major stabilizing effects. Further investigations with different DFT-methods to improve understanding of dispersive and repulsive contributions to $\Delta E_{\mathrm{S}}$ and $\Delta E_{\mathrm{M}}$ are currently in progress.

\section{Acknowledgements}

This work was supported by Deutsche Forschungsgemeinschaft (DFG) under grant "Functional Materials and Materials Analysis for Lithium-High-Performance Batteries” (PAK 177 - Wi 952-7/1), and the German Federal Ministry of Education and Research.

\section{Notes and references}

1 K. Xu, Chem. Rev., 2004, 104, 4303-4418.

2 Y. Wang, S. Nakamura, M. Ue and P. B. Balbuena, J. Am. Chem. Soc., 2001, 123, 11708-11718.

3 J. M. Vollmer, L. A. Curtiss, D. R. Vissers and K. Amine, J. Electrochem. Soc., 2004, 151, A178-A183.

4 V. S. Bryantsev and M. Blanco, J. Phys. Chem. Lett., 2011, 2, 379-383.

5 L. Xing and O. Borodin, Phys. Chem. Chem. Phys., 2012, 14, 12838.

6 K. Tasaki, A. Goldberg and M. Winter, Electrochim. Acta, 2011, 56, 10424-10435.

7 T. Takeuchi, S. Noguchi, H. Morimoto and S. Tobishima, J. Power Sources, 2010, 195, 580-587.

8 X. J. Wang, H. S. Lee, H. Li, X. Q. Yang and X. J. Huang, Electrochem. Commun., 2010, 12, 386-389.

9 Y. Takei, K. Takeno, H. Morimoto and S. Tobishima, J. Power Sources, 2013, 228, 32-38.

10 H. Nakahara, S.-Y. Yoon and S. Nutt, J. Power Sources, 2006, 158, 600-607.

11 H. Nakahara and S. Nutt, J. Power Sources, 2006, 158, 1386-1393.

12 H. Nakahara, M. Tanaka, S.-Y. Yoon and S. Nutt, J. Power Sources, 2006, 160, 645-650.

13 H. Nakahara and S. Nutt, J. Power Sources, 2006, 160, 1355-1360.

14 H. Nakahara, S.-Y. Yoon and S. Nutt, J. Power Sources, 2006, 160, 548-557.

15 T. Inose, S. Tada, H. Morimoto and S. Tobishima, J. Power Sources, 2006, 161, 550-559.

16 Z. Chen, H. H. Wang, D. R. Vissers, L. Zhang, R. West, L. J. Lyons and K. Amine, J. Phys. Chem. C, 2008, 112, 2210-2214. 
17 L. Zhang, Z. Zhang, S. Harring, M. Straughan, R. Butorac, Z. Chen, L. Lyons, K. Amine and R. West, J. Mater. Chem., 2008, 18, 3713-3717.

18 L. Zhang, L. Lyons, J. Newhouse, Z. Zhang, M. Straughan, Z. Chen, K. Amine, R. J. Hamers and R. West, J. Mater. Chem., 2010, 20, 8224-8226.

19 D. E. Fenton, J. M. Parker and P. V. Wright, Polymer, 1973, 14, 589.

20 V. Di Noto, S. Lavina, G. A. Giffin, E. Negro and B. Scrosati, Electrochim. Acta, 2011, 57, 4-13.

21 D. T. Hallinan and N. P. Balsara, Annu. Rev. Mater. Res., 2013, 43, 503-525.

22 Z. Zhu, A. G. Einset, C.-Y. Yang, W.-X. Chen and G. E. Wnek, Macromolecules, 1994, 27, 4076-4079.

23 Z. Zhang, L. J. Lyons, R. West, K. Amine and R. West, Silicon Chem., 2007, 3, 259-266.

24 S. Jeschke, A.-C. Gentschev and H.-D. Wiemhöfer, Chem. Commun., 2013, 49, 1190-1192.

25 S. Jeschke, M. Mutke, Z. Jiang, B. Alt and H.-D. Wiemhöfer, ChemPhysChem, 2014, DOI: 10.1002/cphc.201400065.

26 M. J. Frisch, G. W. Trucks, H. B. Schlegel, G. E. Scuseria, M. A. Robb, J. R. Cheeseman, G. Scalmani, V. Barone, B. Mennucci, G. A. Petersson, H. Nakatsuji, M. Caricato, X. Li, H. P. Hratchian, A. F. Izmaylov, J. Bloino, G. Zheng, J. L. Sonnenberg, M. Hada, M. Ehara, K. Toyota, R. Fukuda, J. Hasegawa, M. Ishida, T. Nakajima, Y. Honda, O. Kitao, H. Nakai, T. Vreven, J. A. Montgomery, Jr., J. E. Peralta, F. Ogliaro, M. Bearpark, J. J. Heyd, E. Brothers, K. N. Kudin, V. N. Staroverov, R. Kobayashi, J. Normand, K. Raghavachari, A. Rendell, J. C. Burant, S. S. Iyengar, J. Tomasi, M. Cossi, N. Rega, J. M. Millam, M. Klene, J. E. Knox, J. B. Cross, V. Bakken, C. Adamo, J. Jaramillo, R. Gomperts, R. E. Stratmann, O. Yazyev, A. J. Austin, R. Cammi, C. Pomelli, J. W. Ochterski, R. L. Martin, K. Morokuma, V. G. Zakrzewski, G. A. Voth, P. Salvador, J. J. Dannenberg, S. Dapprich, A. D. Daniels, O. Farkas, J. B. Foresman, J. V. Ortiz,
J. Cioslowski and D. J. Fox, Gaussian 09, Revision A.02, Gaussian, Inc., Wallingford, CT, 2009.

27 A. D. Becke, J. Chem. Phys., 1993, 98, 5648-5652.

28 C. Lee, W. Yang and R. G. Parr, Phys. Rev. B: Condens. Matter Mater. Phys., 1988, 37, 785-789.

29 T. Clark, J. Chandrasekhar, G. W. Spitznagel and P. V. R. Schleyer, J. Comput. Chem., 1983, 4, 294-301.

30 A. E. Reed and F. Weinhold, J. Chem. Phys., 1983, 78, 4066-4073.

31 A. E. Reed, R. B. Weinstock and F. Weinhold, J. Chem. Phys., 1985, 83, 735-746.

32 A. E. Reed and F. Weinhold, J. Chem. Phys., 1985, 83, 1736-1746.

33 A. E. Reed, L. A. Curtiss and F. Weinhold, Chem. Rev., 1988, 88, 899-926.

34 J. E. Carpenter and F. Weinhold, THEOCHEM, 1988, 169, 41-62.

35 U. C. Singh and P. A. Kollman, J. Comput. Chem., 1984, 5, 129-145.

36 H. Besler, K. M. Merz and P. A. Kollman, J. Comput. Chem., 1990, 11, 431-439.

37 Z. Wang, W. Gao, X. Huang, Y. Mo and L. Chen, J. Raman Spectrosc., 2001, 32, 900-905.

38 P. Johansson, M. Edvardsson, J. Adebahr and P. Jacobsson, J. Phys. Chem. B, 2003, 107, 12622-12627.

39 V. Sládek, V. Lukeš, M. Breza and M. Ilčin, Comput. Theor. Chem., 2011, 963, 503-509.

40 S. Grigoras and T. H. Lane, J. Comput. Chem., 1987, 8, 84-93.

41 H. Niedermeyer, M. A. Ab Rani, P. D. Lickiss, J. P. Hallett, T. Welton, A. J. P. White and P. A. Hunt, Phys. Chem. Chem. Phys., 2010, 12, 2018-2029.

42 K. Hashimoto and T. Kamimoto, J. Am. Chem. Soc., 1998, 120, 3560-3570.

43 J. Romero, A. Reyes, J. David and A. Restrepo, Phys. Chem. Chem. Phys., 2011, 13, 15264-15271.

44 L. F. Holroyd and T. van Mourik, Chem. Phys. Lett., 2007, 442, 42-46. 